\title{
Communicating Science and Technology. Gradiva's Books of Popularization of Science and Technology and the Portuguese Public ${ }^{1}$
}

\author{
Inês N. Navalhas \\ Centro Interuniversitário de História das Ciências e da Tecnologia (CIUHCT), \\ Faculdade de Ciências e Tecnologia, Universidade NOVA de Lisboa \\ i.navalhas@campus.fct.unl.pt
}

\begin{abstract}
By focusing on the books of popularization of science and technology published by Gradiva this research aims at understanding the mechanisms and strategies to bring science and technology to a broader audience in Portugal, after 1974, the year of the Carnation Revolution that put an end to a long half century dictatorship. I use a mix conceptual framework: on the one hand, I use the scientific literacy and public understanding of science and technology main references to explore the public's behavior and opinion concerning scientific and technological knowledge; on the other hand, I analyze Gradiva's choices concerning the collections aimed at popularizing science and technology. So, I hope to contribute to map the perception of the Portuguese public about techno-scientific themes that influence their life and decisions, to understand how scientists relate to scientific and technological popularization literature and to assess scientific literacy in the Portuguese population.
\end{abstract}

Keywords: scientific and technological communication, scientific literacy, public understanding of science, scientific books, Gradiva

\footnotetext{
${ }^{1}$ This Work in Progress is based on my on-going PhD research project, supervised by Professors Maria Paula Diogo and Paula Urze, at Faculty of Sciences and Technology of the NOVA University of Lisbon, Portugal (DCSA, FCT/NOVA), Doctoral Program of History, Philosophy and Heritage of Science and Technology, with a CIUHCT scholarship under the program "Inter-university Centre for the History of Sciences and Technology" (UID/HIS/00286/2019).
}

(C) 2019 Inês N. Navalhas. This is an open access article licensed under the Creative Commons Attribution-NonCommercial-NoDerivs License (http://creativecommons.org/licenses/by-nc-nd/3.0/). 


\section{Scientific literacy: an ongoing debate}

My PhD research project aims at understanding the mechanisms and strategies to bring science and technology to a broader audience in Portugal, after 1974, the year of the Carnation Revolution that put an end to a long half century dictatorship. At the core of my research are the collections published by Gradiva in the realm of popularization of science and technology.

The relevance of communicating science and technology ( $\& \& T)$ to wide and lay audiences has a long tradition in Europe and has been critical in building the relationship between knowledge, happiness and progress that is at the core of the modern European identity. ${ }^{2}$ The eighteenth-century twenty-eight widely illustrated volumes of the Encyclopédie, edited by Jean d'Alembert and Denis Diderot, establish the paradigm of the culture scientifique, bringing together the available knowledge in concise and clear articles written by specialists and accessible to all audiences, including non-specialist audiences. Although more restrictive, the salons played the same role offering, often under the patronage of aristocrats, a space for scientific and technological experiments and debates among scientists, technologists and an educated non-specialized public. ${ }^{3}$

Throughout the nineteenth century, science and technology became part of urban daily life, as well as a symbol of social mobility. ${ }^{4}$ World exhibitions, books on the lives of "great" scientists and engineers (e.g., Louis Figuier's Les Merveilles de l'Industrie and Lives of the Engineers by Samuel Smiles) and science fiction (e.g. A Journey to the Center of the Earth by Jules Verne or The Time Machine of H.G. Wells) strongly contributed to assert among the lay public both the idea of a user friendly science and technology and the myth of free-floating research with the only goal of promoting social well-being. The twentieth century and particularly the two World Wars proved this idea wrong. Knowing that science and technology had inherent risks and the growing need for major funding led the governments to realize that public opinion was a critical actor to achieve recognition and legitimation of research and its risks. ${ }^{5}$ Hence the public debate on S\&T in the twentieth century changed according to political, social and economic agendas and contexts, spanning from an optimistic and generalized perspective to

\footnotetext{
2 On communication of science and technology, see Ana Simóes, ed. "Communicating science, technology and medicine," Special issue, HoST - Journal of History of Science and Technology, 6 (Fall 2012), and particularly Ana Simóes, "Introduction: communicating science, technology and medicine," HoST - Journal of History of Science and Technology 6 (2012): 9-14.

3 Suzana Mueller and Rita Caribé, "Comunicação científica para o público leigo: Breve Histórico," Londrina 15 (2010): 13-30.

${ }^{4}$ David Knight, Public Understanding of Science - A History of Communicating Scientific Ideas (New York: Routledge, 2006), 3; Bernard Schiele, When science becomes culture-World survey of scientific culture (Ottawa: University of Ottawa Press, 1994), 209.

${ }^{5}$ Ulrich Beck, Risk society — Towards a new modernity (London: Sage Publications, [1986], 1992); Brian Wynne, "Misunderstood Misunderstanding: Social Identities and Public Uptake of Science," Public Understanding of Science 1, no. 3 (1992): 281-304, on 300.
} 
a skeptical and pessimistic view of S\&T's role in modern society. ${ }^{6}$ In both cases, however, explicitly or not, the question of scientific literacy remained at the core of the discussion. As democratic decision-making implies knowledge and being able to deal with information, the awareness of the existence of a scientific literacy deficit becomes crucial to understand the public's lack of confidence in S\&T: the bigger the deficit is, the more pessimist the general public tends to be. ${ }^{7}$

The post-World War II surveys on public opinion on S\&T carried out in the United States and those on the 1970s in the United Kingdom opened up a new paradigm of dealing with the question of the "deficit model," commonly known as public understanding of science (PUS) that promoted the growth of scientific culture in society at large. In 1985, the Royal Society published the report The Public Understanding of Science which is considered a landmark regarding the relationships between the scientific community and the civil society. ${ }^{8}$ The report encouraged pro-active policies for promoting science and technology across society using the media and the training of scientists as communicators.

Although the concept of public understanding of science is more complex, dense and wider than the one of popularization of science, some of the instruments used to enlarge the audiences' interest in science and technology are the same. Books written to popularize scientific theories otherwise too difficult to be understood by non-specialists - e.g. quantum physics, relativity, evolution of different species - are one of the many visible faces of this intricate and difficult process.

This topic received significant international attention, ${ }^{9}$ but in Portugal it is still largely

\footnotetext{
${ }^{6}$ Donghong Cheng, Michel Claessens, Toss Gascoigne, Jenni Metcalfe, Bernand Schiele, and Shunke Shi, eds., Communicating Science in Social Contexts - New models, new practices (New York: Springer, 2008); Meinolf Dierkes, Claudia von Grote, eds., Between Understanding and Trust - The Public, Science and Technology (London: Routledge, 2000), 18.

7 David Dickson, "The case for a 'deficit model' of science communication," paper presented at the Public Communication of Science and Technology Working Symposium on Strategic Issues in Science and Technology Communication, Beijing, China, 22 June 2005, 2; Bruce Lewenstein, "Models of public communication of science and technology," Public Understanding of Science 96, no. 3 (2003): 288-293; Massimiano Bucchi and Federico Neresini, "Science and Public Participation," in The Handbook of Science and Technology Studies, ed. Edward J. Hackett, Olga Amsterdamska, Michael Lynch and Judy Wajcman, 449-472 (Cambridge: MIT Press, 2008), 450.

${ }^{8}$ Royal Society, The Public Understanding of Science (London: The Royal Society of London, 1985).

9 For a contribution on scientific books see Agusti Nieto-Galan, Los Públicos de la Ciência. Expertos y profanos através de la historia (Madrid: Marcial Pons, 2011); Agusti Nieto-Gálan, Science in the Public Sphere (London: Routledge, 2016), Faidra Papanelopoulou, Agusti Nieto-Gálan, and Enrique Perdiguero, Popularizing Science and Technology in the European Periphery, 1800-2000 (London: Routledge, 2009); Rex Buchanan, "Books and the Popularization of Science," Publishing Research Quarterly 7, no. 1 (1991): 5-10; Elia Ben-Ari, "When scientists write books for the public," Bioscience 49, no. 10 (1999): 819-824.
} 
unexplored. ${ }^{10}$ My research aims at filling this lack of information and scholarship, crisscrossing the territories of History, Sociology and Communication of Science and Technology. To achieve my goal, I focus on two very different kind of sources which, in turn, imply two methodological approaches. On the one hand, in the context of the current scholarship in History of Science and Technology, I use the scientific literacy and public understanding of science and technology references (in an expert/lay public relationship) to explore the public's behavior and opinion concerning scientific and technological knowledge and its relevance to general well-being; on the other hand, I analyze the publisher Gradiva's choices concerning the collections aimed at popularizing science and technology, using a text and content driven analysis. This mixed methodological approach seems to be the most fruitful as it allows the use of combined qualitative and quantitative data. ${ }^{11}$ In a nutshell, I use the framework of History of Science and Technology and particularly concepts such as public opinion, social control of technology, progress, well-being and utilitarianism to design the questions I want to ask "my" sources - Gradiva's collections and the public - and to interpret the answers I receive.

At the end of the day I hope to contribute to map the perception of the Portuguese public about techno-scientific themes that influence their daily life and their decisions in the context of the post-dictatorship Portuguese society, to better understand how scientists relate to scientific and technological popularization literature and to assess scientific literacy in the Portuguese population.

\section{Publishing for the people in democratic times: Gradiva's books of popularization of science}

Stephen Hawking's Brief History of Time or Carl Sagan's Cosmos were successful examples of how to get wide audiences interested in science. However, not all scientists are as successful at selling their stories as Hawking or Sagan. A significant part of scientists that write S\&T dissemination books assume that they write primarily to share their fascination and personal experiences and not because they expect the public to be interested in the scientific topics of their books. ${ }^{12}$ Books on science and technology targeting lay audiences do not have a large amount of readers, since only an attentive public is interested in reading them. ${ }^{13}$

\footnotetext{
${ }^{10}$ See Carlos Fiolhais, A Ciência em Portugal (Lisboa: Fundação Francisco Manuel dos Santos, 2011); and António Granado and José Vítor Malheiros, Cultura Cientifica em Portugal (Lisboa: Fundação Francisco Manuel dos Santos, 2015), to understand the portuguese context of scientific popularization books.

${ }^{11}$ Clara Pereira Coutinho, Metodologia de Investigação em Ciências Sociais e Humanas: Teoria e Prática, 2nd ed. (Coimbra: Almedina, 2016).

12 Ben-Ari, "When scientists," 819.

13 Buchanan, "Books," 7; Bucchi and Neresini, "Science and Public Participation," 458.
} 
In Portugal, books aiming at popularizing scientific subjects to a general medium educated audience gain momentum from the 1980s onwards as science emerged as a topic of interest in Portuguese society. ${ }^{14}$ There is obviously a past concerning these efforts that goes back to the eighteenth century and continues throughout the nineteenth and the twentieth centuries. Teodoro de Almeida’s Recreaçóes Filosóficas (Philosophical Recreations), written from 1786 to 1800, explicitly targeted lay audiences by adding as subtitle Dialogo sobre a filosofia natural, para instrucção de pessoas curiosas, que não frequentárão as aulas (Dialogue on natural philosophy for the education of curious people, who did not attend classes); ${ }^{15}$ building up on the nineteenthcentury science and technology texts written in a simple way for educational purposes, the Republican regime (implemented in 1910) deployed a set of strategies - including books - to bring science to the people as a way of strengthen its ideological commitment to republican values; ${ }^{16}$ in 1941, as a form of resistance and defying the authoritarian regime of the Estado Novo, the mathematician Bento de Jesus Caraça launched the Biblioteca Cosmos (Cosmos book collection) that aimed at providing information on cultural topics to a broad audience and whose section 1 was fully dedicated to science and technology; ${ }^{17}$ along the same lines knowledge as the corner stone of citizenship and freedom -; in the late 1940s Rómulo de Carvalho published the book collection Ciência para Gente Nova (Science for Young People) dedicated to high school students. ${ }^{18}$

This tradition was picked up by the publisher Gradiva after the political shift of Portugal towards democracy (1974), in a context of a growing process of massification of education and a significant decline in the levels of illiteracy among the Portuguese population. ${ }^{19}$

\footnotetext{
${ }^{14}$ Fiolhais, A Ciência, 78-79; Ângela Salgueiro, Ana Carina Azevedo, and Maria Fernanda Rollo, Em Nome da Ciência: Ciência Viva - Agência Nacional para a Cultura Científica e Tecnológica. 20 anos de História (1996-2016) (Lisboa: Imprensa Nacional-Casa da Moeda, 2017).

${ }^{15}$ José Alberto Silva, "A vulgar Recreation," HoST - Journal of History of Science and Technology 6 (Fall 2012): $15-32$.

${ }^{16}$ Ana Simóes, Isabel Zilhão, Maria Paula Diogo, and Ana Carneiro, "Halley turns Republican. How the portuguese press perceived the 1910 return of Halley's comet," History of Science 51 (2013): 199219; Ana Simôes, Maria Paula Diogo, "Ciências para o Povo: espaços de ensino superior para adultos na Lisboa Republicana," in Lisboa Capital Cientifica, eds. Tiago Saraiva and Marta Macedo (Lisboa: ICS, 2019, forthcoming). Preprint with the authors' permission.

${ }^{17}$ Manuel Rodrigues de Oliveira, "Biblioteca Cosmos," in "Bento de Jesus Caraça no $20^{\circ}$ aniversário da sua morte - presença e actualidade," Seara Nova 1472 (June 1968): 181-192.

${ }^{18}$ Carlos Fiolhais, Urbano T. Rodrigues, Natália Nunes, Nuno Crato, Rogério Fernandes, Luísa D. Soares, and Teresa A. Nunes, Estudos sobre o autor: Rómulo de Carvalho (Lisboa: Biblioteca Nacional, 2006).

19 The Portuguese rates of illiteracy were always very high when compared with other European countries. In 1890, around 75 percent of the population could not read or write; in the 1970s this rate still reached the 25 percent of the population (1 in 4); and in 1991, according to the census, it was around 12.5 percent. Rui Grácio, "Ensino Primário e Analfabetismo," in Dicionário de História de Portugal, vol. 2, ed. Joel Serrão, (Lisboa; Iniciativas Editoriais, 1971), 51.
} 


\section{Scientific and technological popularization books}

The Portuguese publisher Gradiva publishes three collections focused on science and technology: Ciência Aberta (Open Science), Trajectos (Paths) and Panfletos (Pamphlets). It has been in the market for about thirty years and has published some of the best-sellers in the realm of books of popularization of science and technology. The first step of my work was to map all of the titles in Ciência Aberta and to design an analysis grid to collect data from the books. This grid has a quite large number of indicators for each book and include both formal and content data aiming at building a clear picture on how scientific and technological knowledge is conveyed by this type of books.

Concerning formal aspects, the grid begins by the title (both original and translated if that is the case), its author(s), the biography of the author (geographical and academic provenance), the year of publication (both original and the translated version, if any), the translators and the scientific reviewers of the translation and the main theme and subthemes (e.g. physics as theme and theory of relativity or physics laws as subtheme). Other indicators under scrutiny are the index (if any) and the books' formal organization (chapters, titles, subtitles), as well as the preface and its authorship (the book's author or other(s), the existence, the type and the number of images (graphics, illustrations, schemes or photos). Regarding the design and image of the book, we note the authorship of the book's covers and of the photocomposition.

The analysis of the content of the book allows us to identify the writing style of the authors (e.g. formal or colloquial writing), simple or difficult reading (use or not of technical jargons), the length of the sentences, whether it is a chronicle, a history with characters or just a description of the events or phenomena.

By exploring Ciência Aberta through these set of markers I will map the interrelationships between them and how do they prove (or not) my research hypotheses. Just a few examples: which is the average time between the original publication and its translated version in Portugal and to what extent can this time lag be a symptom of scientific culture running at a slower pace and delayed in comparison with other editions in other countries; are there any dominant areas and if yes do they vary according to the esprit du temps or to hot social topics; who translates the books, how often the same translator is used and do they specialized in specific areas. 
The information channeled by these indicators will be analyzed using the content analysis technique and is deemed critical to seize the "what" and the "how" of the popularization of science and technology literature in Portugal. ${ }^{20}$

\section{Stakeholders in the scientific and technological popularization process}

Given that we are exploring one of Gradiva's collection, it is imperative to know the perspective of its key players, namely Guilherme Valente, the first Ciência Aberta's editor (up to book number 200) and his successor, Carlos Fiolhais, an acknowledged Portuguese physicist, science communicator and author of popular S\&T divulgation books (some published by Gradiva). These more personal insights are to be collected during semi-structured interviews, that allow to focus on specific questions - for instance the publishers' relationship with science and technology or the criteria of their choices - while still keeping the necessary space for spontaneous informal dialogue.

The same methodology will be applied to the "producers" of S\&T popularization books, namely Portuguese authors such as Jorge Dias de Deus, Jorge Buescu, David Marçal, Rita Marnoto, João Magueijo or Alexandre Aibéo, thus ranging from mathematicians to astronomy or physicists. In this case it is important to understand the authors' motivations for writing this kind of books, their perception of the public that reads them, their assessment of the impact their books have on the general public, their decision on the style they use to communicate.

These semi-directive interviews - already being held - were designed in an early phase of the $\mathrm{PhD}$ project and allow for collecting information that would escape if made by a questionnaire. Face-to-face (whenever possible) or skype interviews are, as mentioned, underway; they are recorded, filmed and transcribed and later sent to the interviewees so that they can attest to their accuracy. ${ }^{21}$ Again, content analysis ${ }^{22}$ is used as a way of codifying the data resulting from the interviews and enhance the interviewee's perspective on the topic of investigation.

\footnotetext{
${ }^{20}$ This exploratory technique will be carried out in three consecutive moments: 1) pre-analysis, where the data will be organized, following its completeness, representativeness, pertinence and homogeneity and exclusivity; 2) data mining will be the analysis phase where the raw data is processed with the research objective as stating point; 3) treatment of results where the data collected according to their validity and fidelity will be interpreted. See Laurence Bardin, Análise de Conteúdo (Lisboa: Ediçóes 70, 1970).

${ }^{21}$ Coutinho, Metodologia, 140.

${ }^{22}$ Rodolphe Ghiglione and Benjamin Matalon, O Inquérito - Teoria e Prática, 3rd ed. (Oeiras: Celta, 1977).
} 


\section{The public perception of science and technology through questionnaires}

In a third stage, the public - considered as potential consumer of S\&T popularization books plays a fundamental role in the research since one of my objectives is, precisely, to understand how lay public perceives science and technology and its relevance in today's society.

Using as main references the framework developed under the concepts of scientific literacy and public understanding of science and taking into account the specificities of the Portuguese case, I am designing a questionnaire survey targeting large groups ${ }^{23}$ in order to obtain a large quantity of information - a significant sample - that will allow for measuring attitudes, perceptions and opinions. This low-cost self-administered questionnaire will use communication technologies and social networks to collect information in a quick pace and will cover the Lisbon Metropolitan Area (LMA), using the representative sample technique based on the identification of subgroups, sampling procedures and sample selection. Sampling will be stratified and probabilistic, since the total population will be organized into categories or strata and the possibility of representing each stratum will be analyzed. In this case, sampling may become a quota if its representativeness is proportional. ${ }^{24}$ The geographical area covered by the survey includes both rural and urban spaces, with very different demographic, educational, economic, social and political profiles, thus ensuring the diversity of data necessary to have an inclusive and significant universe of analysis.

As mentioned above, the purpose of this survey is to prone in a quantitative way the perceptions, opinions, beliefs, attitudes and scientific and technological literacy of the Portuguese public. In this context, the study by the scholars Martin Bauer and Susan Howard, which compares the perceptions of the Portuguese public with the other European countries with regard to S\&T, is an important auxiliary document in this construction phase, as well as Eurobarometer surveys on science in society. ${ }^{25}$

Together with the more canonic variables used to characterize the sample - gender, age, geographic distribution within the LMA or educational level - I include additional ones aiming to unveil the reading habits in general and concerning $S \& T$, the awareness of the existence of Gradiva or other publishers in the same market segment and of Ciência Aberta or other collections, the level of scientific literacy and the willingness to improve it, the perception of science and technology as a positive or a negative player in contemporary society and the sheer definition(s) the lay public has of what is science and technology and how do they evolve.

\footnotetext{
${ }^{23}$ See Coutinho, Metodologia, 139-140.

${ }^{24}$ See Ibid., 89-103.

25 Martin W. Bauer and Susan Howard, Modern Portugal and its Science Culture - Regional and Generational Comparisons (London: LSE, 2014).
} 
After the data is collected, I will proceed to the statistical analysis of the data, relating them to the conceptual framework of the project and my main research questions, namely concerning the relationship between $S \& T$ and society at large as well as the role of books of popularization of science and technology in the construction of the public perception of science and technology in present time.

\section{Final remarks}

My $\mathrm{PhD}$ research uses the case study of the publisher Gradiva to evaluate the impact of books of popularization of science and technology in building scientific and technological literacy in Portugal. The relevance of the accessibility of S\&T knowledge by a non-specialist public is also discussed, both in terms of the perception built on the importance of S\&T for general wellbeing and as basis for an active and participative citizenship in the face of scientific research options, as well as a way to stimulate new generations of socially responsible scientists and engineers.

On a broader side, my research is also looking to contribute to the national and international debate within the History of Science and Technology on the issue of the expert/lay public relationship, thus expanding the existing scholarship on Portuguese audiences of S\&T, their main actors and agendas. Parallel to these academic objectives, this study will also contribute to provide guidelines for policy-makers concerning the access of civil society to scientific and technological knowledge in a context of a growing demand for social control of science and technology. As public funding for research both at a national and European level rises, the relevance of democratizing public decision-making processes also becomes increasingly important. It is an ongoing process, which begins by establishing an efficient two-way communication between the public and the scientists and technologists and may even, with the advent of new technologies, end in an innovative participation in the legislation and production of science itself.

As a result of my $\mathrm{PhD}$ research, I intend to promote a set of initiatives to disseminate the results in order to raise awareness among the public and stakeholders of the importance of a fruitful relationship between $S \& T$ and society. 